
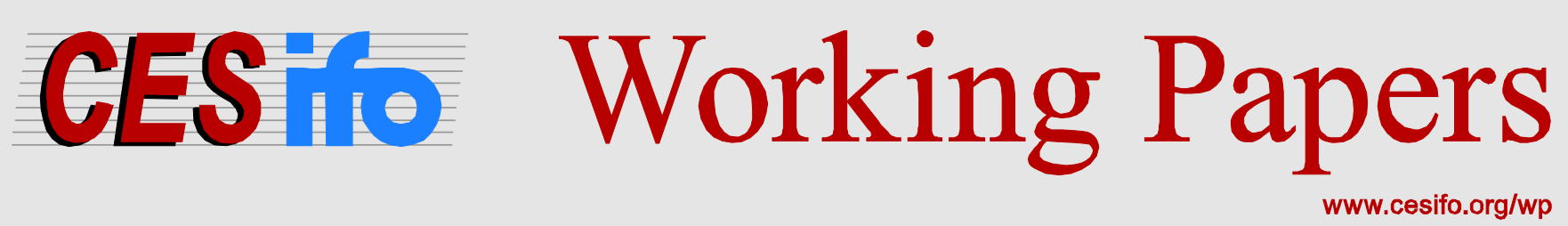

\title{
Public Investment when Capital is Back - Distributional Effects of Heterogeneous Saving Behavior
}

\author{
Linus Mattauch \\ Ottmar Edenhofer \\ David Klenert \\ Sophie Bénard
}

CESIFO WORKING PAPER NO. 4714

CATEGORY 1: Public FinANCE

MARCH 2014

An electronic version of the paper may be downloaded

- from the SSRN website:

- from the RePEc website:

- from the CESifo website:

www.SSRN.com

www.RePEc.org

www.CESifo-group.org/wp

\section{CESifo}




\title{
Public Investment when Capital is Back - Distributional Effects of Heterogeneous Saving Behavior
}

\begin{abstract}
We study the impact of heterogeneous saving behavior on the distributional effects of public investment. A capital tax is levied to finance productive public capital in an economy with two types of households: high income households who save dynastically and middle income households who save for retirement. We find that inequality is reduced the higher the capital tax rate and that low rates even constitute a Pareto-improvement. There is thus no clear-cut trade-off between efficiency and inequality: middle income households' consumption is maximal at a higher capital tax rate than high income households' consumption.
\end{abstract}

JEL-Code: E600, H230, H310, H400, H540.

Keywords: public capital, wealth disparity, inequality, household heterogeneity, Pasinetti Paradox, saving behavior.

Linus Mattauch*

Mercator Research Institute on Global

Commons and Climate Change (MCC)

Torgauer Str. 12-15

Germany - 10829 Berlin

mattauch@mcc-berlin.net

David Klenert

Potsdam Institute for Climate Impact

Research (PIK)

Postbox 601203

Germany - 14412 Potsdam

klenert@pik-potsdam.de
Ottmar Edenhofer

Potsdam Institute for Climate Impact

Research (PIK)

Postbox 601203

Germany - 14412 Potsdam

ottmar.edenhofer@pik-potsdam.de

\author{
Sophie Bénard \\ Technical University Berlin \\ Berlin / Germany
}

*corresponding author

March 4, 2014 


\section{Introduction}

Capital taxation has for a long time not been favored by economists as a revenue-raising option. Now "capital is back" (Piketty and Zucman, 2013) as a factor to be taxed for financing public investment in developed countries: on the one hand, the capital-output ratio increases (Piketty, 2014) which in part explains great wealth disparities (Wolff, 2010). On the other hand public investment may significantly enhance aggregate productivity (Romp and De Haan, 2007). For the distributional consequences of financing public investment by capital taxation, household heterogeneity in saving motives (Browning and Lusardi, 1996; Dynan et al., 2004) and income sources (Wolff, 1998) should crucially influence the outcome of fiscal policy, but previous analyses have neglected such heterogeneity. This article introduces a model of two stylized types of households that differ in saving motives and income source to study the effect of financing productive public investment by a capital tax. It answers the following question: is it possible to invest in public capital in a way that all households benefit while the financing mechanism mitigates inequality? The answer is yes when there is significant underprovision of public investment and it is financed by a capital tax. We also prove that wealth inequality is mitigated by the capital tax and that for each household type, a different rate of capital taxation is optimal.

Previous theoretical work on the provision of public capital has focused on homogenous households. It has emphasized that a trade-off exists between investment into productive public capital and efficiency losses from taxes financing these investments. This trade-off determines an optimal tax rate (Barro, 1990). When household heterogeneity is taken into account to study the effects of public investment on inequality, all agents are typically assumed to have identical preferences, while the heterogeneity stems from different initial endowments. For example, Alesina and Rodrik (1994) show that when households differ by the division of their endowment in wealth and (inelastic) labor supply, growth is always reduced by capital taxation aimed at reducing inequality, although households with higher labor to capital ratio prefer higher capital taxes. On the contrary, Chatterjee and Turnovsky (2012) find that, when public investment also affects the labor-leisure decision of households, investing in public capital increases inequality in wealth in the long run, but also growth and average welfare, independent of the financing mechanism. However, the growth rate determines whether inherited wealth matters relatively more than labor income for the wealth distribution (Piketty, 2011). This indicates that household heterogeneity in income sources and saving motives must be taken into account for robust conclusions about the distributional effects of public investment. 
Here we introduce a model of productive public capital and wealth inequality in which the heterogeneity stems from different saving motives and income sources and there are two different types of households: high income households, whose only source of income is the interest from their capital stock, save dynastically and are represented by infinitely-lived agents. Middle income households live for two periods, have labor income in the first period and save for retirement; they are modeled as overlapping generations. A capital tax is levied by the government to finance productive public investment. In this situation we prove the following results: first, the higher the capital tax, the higher the share of capital owned by the middle income households, thus mitigating inequality in wealth. Second, there is not one optimal level of capital taxation, but each type of household desires a different level. Middle income households are more favorable to the investment in public capital and desire a higher capital tax rate than high income households. Third, a Pareto-improving capital tax rate exists nevertheless: for low tax values, both classes are made better off as long as there is little public investment provided. The results together imply that there is no clear trade-off between equity and efficiency.

Our model is related to that presented in Michl $(2009)^{1}$, in which the author models different saving behavior across classes similarly, but evaluates the outcome in a classical context to assess different social security schemes. In particular, both contain a version of the 'Pasinetti Paradox': In the steady-state one type of households determines the interest rate (Pasinetti, 1962). Our first result is a consequence of this property.

The division of households into two types with respect to their saving behavior can be justified as follows. It is well-known that there are striking wealth disparities within developed economies; for example Wolff (2010) finds for the U.S. that the wealthiest $5 \%$ of the population own roughly $62 \%$ of total wealth, the next $55 \%$ of the population own close to the remaining $38 \%$, while the rest of the population owns virtually no wealth. These groups can be distinguished by different saving motives: Attanasio (1994) analyzes the saving behavior of different income cohorts in the U.S. and finds that the wealthiest cohort in the above mentioned study saves dynastically. Dynan et al. (2004) find a mixture of bequest and precautionary motives as the main drivers of savings of the wealthiest households. They also find that each motive in isolation yields almost the same outcome as a combination of both. Moreover, the wealthiest individuals are known to be typically self-

\footnotetext{
${ }^{1}$ Michl and Foley (2004) and Michl (2009) label the income classes 'capitalists' and 'workers' respectively. We refrain from these terms not only to avoid invoking unhelpful rhetoric of class conflict, but also for the fact that 'workers' typically have no bequest motive. 'Workers' seems rather a term appropriate to low income households, who are not modeled here, as they do not save and thus do not own a part of the capital stock of the economy.
} 
employed entrepreneurs (Wolff (1998) finds that 72 percent of the richest $1 \%$ were self-employed entrepreneurs for data on U.S. households for 1995.).

The middle part of the wealth distribution is known to save in a life-cycle fashion (Attanasio, 1994; Browning and Lusardi, 1996), that is accumulates wealth while employed and dissaves when retired. Moreover, lower income households are also supposed to have higher time preference rates (Lawrance, 1991).

These empirical findings suggest dividing households into three groups with distinctly different saving motives: The poorest households do not save - and are hence excluded from our analysis as the benefits they may have from public investment are unlikely to affect their saving behavior. The cohorts in the middle of the wealth distribution save mainly for their retirement and are thus best represented as overlapping generation agents that have income from both labor and capital. The wealthiest income cohorts are mainly self-employed and save dynastically, which suggests that they should be modelled as infinitely-lived households who have income from capital only. Variants of this stylized classification are also used by Mankiw (2000) and Michl (2009).

The remainder of this article is structured as follows: Section 2 sets out the model. Section 3 presents its steady-state properties, contains the derivations of the analytical results and the numerical estimates. Section 4 summarizes the distributional properties of the model and mentions possible extensions.

\section{Model}

We model a one-good economy in which the government can finance public capital that enhances productivity. The population consists of two classes, high income households and middle income households. The representative middle income household provides labor when its members are young and they save for retirement; the household leaves no bequests. Middle income households are modelled as overlapping generations. The representative high income household holds capital and interest is its sole source of income. It has a dynastic saving motive and is thus modeled as an infinitely lived agent. Both types of agents derive utility from consumption only. Factor markets clear and on the capital market, the supply consists of both high income households' investment and middle income households' savings. There are decreasing returns to scale in private and public capital, but constant returns to scale in private capital and labor. We first describe the household's behavior before detailing the role of the firms and the government. 
High income household The high income household owns a capital stock $K_{t}^{c}$ and maximizes intertemporal utility given by

$$
\sum_{t=0}^{\infty} \frac{1}{\left(1+\rho_{c}\right)^{t}} \ln \left(C_{t}^{c}\right)
$$

with consumption $C_{t}^{c}$ and time preference rate $\rho_{c}$. Its budget constraint is

$$
K_{t+1}^{c}-K_{t}^{c}=(1-\tau) r_{t} K_{t}^{c}-C_{t}^{c},
$$

where $r_{t}$ is the interest rate and $\tau$ is the capital tax.

The initial capital stock is given as $K_{1}^{c}=K_{0}^{c}$. The high income household respects a transversality condition: $\lim _{t \rightarrow \infty}\left(K_{t}^{c} \prod_{s=1}^{t-1} \frac{1}{1+r_{s}}\right) \geq 0$.

Solving the maximization problem yields the Euler equation

$$
\frac{C_{t+1}^{c}}{C_{t}^{c}}=\frac{1+(1-\tau) r_{t+1}}{1+\rho_{c}} .
$$

Middle income household The middle income household lives for two periods, a 'young' (y) and an 'old' (o) stage. It maximizes their lifetime utility, where utility from consumption in the second period is discounted by the time preference rate $\rho_{w}$ :

$$
\ln \left(C_{t}^{y}\right)+\frac{1}{1+\rho_{w}} \ln \left(C_{t+1}^{o}\right)
$$

In the first period, the middle income household rents its fixed labor to the producing firm, which in turn pays a wage rate $w_{t}$. Labor income can either be consumed or saved for the old age:

$$
w_{t} L=S_{t}+C_{t}^{y} .
$$

In the second period the middle income household consumes its savings and the interest on them:

$$
C_{t+1}^{o}=\left(1+(1-\tau) r_{t+1}\right) S_{t} .
$$

Solving the optimization problem subject to the budget constraints leads to the Euler equation:

$$
\frac{C_{t+1}^{o}}{C_{t}^{y}}=\frac{1+(1-\tau) \cdot r_{t+1}}{1+\rho_{w}}
$$

From Equations (5-7) explicit expressions for saving and consumption in the two periods can be derived:

$$
S_{t}=\frac{1}{2+\rho_{w}} w_{t} L
$$




$$
\begin{gathered}
C_{t}^{y}=\left(\frac{1+\rho_{w}}{2+\rho_{w}}\right) w_{t} L \\
C_{t+1}^{o}=\left(\frac{1+(1-\tau) r_{t+1}}{2+\rho_{w}}\right) w_{t} L .
\end{gathered}
$$

The savings rate is constant, as is standard in discrete OLG models when the utility function is logarithmic. The same is true for the consumption of the young agent, while $C_{t+1}^{o}$ is still dependent on the interest rate r. Moreover, combining Equations (8-9) implies that $C_{t}^{y}$ depends linearly on savings $S$.

Production The firm produces output according to a Cobb-Douglas production function. Public capital enhances productivity of both factors:

$$
F\left(K_{t}, L\right)=A_{t} K_{t}^{\alpha} L^{1-\alpha}
$$

with $A_{t}=P_{t}^{\beta}$ and $0<\alpha, \beta<1$. Throughout we assume $\alpha+\beta<1$ to exclude the case of long-run or explosive growth.

$K_{t}$ denotes the sum of the individual capital stocks

$$
K_{t}=K_{t}^{c}+S_{t-1}
$$

and $\beta$ is the efficiency factor of public capital $P_{t}$. Profit maximization yields the standard rates of return for capital and labor:

$$
\begin{gathered}
r_{t}+\delta_{K}=\frac{\partial F\left(K_{t}, L\right)}{\partial K_{t}}=\alpha \frac{F\left(K_{t}, L\right)}{K_{t}} \\
w_{t}=\frac{\partial F\left(K_{t}, L\right)}{\partial L}=(1-\alpha) \frac{F\left(K_{t}, L\right)}{L} .
\end{gathered}
$$

Government The sole function of the government in this model is the provision of public capital. It finances its investments by the capital tax, thus influencing the interest rate. Hence the government's activity is summarized as the change in the stock of public capital:

$$
P_{t+1}=P_{0}+\left(1-\delta_{P}\right) P_{t}+\tau r_{t} K_{t}
$$

For the following results, we assume

$$
P_{0}=0 .
$$

We later confirm numerically that even if a minimal provision of public good $P_{0}>0$ is present without government intervention, our qualitative results do not change and we provide numerical results on the significance of $P_{0}$. 


\section{Results}

In this section we show that inequality in wealth is mitigated by a capital tax levied for public investment in our model. We also characterize the optimal tax rate for each household type: the middle income household is more favorable to capital taxation and higher public investment than high income household. We point out that low capital tax rates lead to a Pareto-improvement, even for the case in which the economy is functioning without any public investment. First, we characterize the steady-state and the validity range of the model. We then prove the results just stated. Finally the model is calibrated and analyzed numerically to determine the optimal tax rates that cannot be calculated explicitly and to examine the role of potential non-publicly provided existing infrastructure. Figures 1 and 2 below illustrate the main findings.

\subsection{Steady state and validity range}

In our model, a version of the "Pasinetti Paradox" holds because the high income household's sole income is capital interest. In a model with two types of households, in which one household only receives income from capital "the capitalists" -, the Pasinetti Paradox (Pasinetti, 1962; Samuelson and Modigliani, 1966) states that the "capitalists" will determine the steady state interest rate independently of the savings rate of the other household type or the production technology.

In a neoclassical setting with exogenous savings rates, Samuelson and Modigliani (1966) show as an extension of this result that in a steady-state one of the following regimes must hold: (i) the savings rate of the "capitalists" determine the interest rate or (ii) the "capitalists" do not have any capital at all. In the steady-state of our model we find a similar duality although the saving behavior of our household types is derived from their intertemporal preferences: Either (i) the high income household determines the steady-state interest rate or (ii) its capital stock and consumption is zero and the economy is only populated by middle income households. Which regime holds in the steady-state of our model depends on its parameters. In the following analysis, we are exclusively concerned with (the applicable) case (i). We study the effect of the capital tax on the wealth distribution and call the tax rate at which the high income household's share of capital approaches zero, the limit of case (i), the model's validity limit.

The (unique non-trivial) steady-state is saddle-point stable and the economy converges to it on a stable path because the capitalist's behavior determines the overall dynamics. ${ }^{2}$ The Pasinetti-type behavior of the model in

\footnotetext{
${ }^{2}$ A heuristic argument for saddle-point stability is as follows: The dynamics of the model are captured by four Equations for the variables $K^{c}, C^{c}, P$ and $K$, namely Equations (2), (3), (14) and substituting Equation (8) into Equation (11). If it were the case that
} 
the steady-state can be explained as follows: The high income household's saving behavior determines the interest rate because reducing or increasing its investment is its only means of obtaining its desired long-term distribution of consumption to capital. Any attempt of the middle income household to obtain a different interest rate would thus be balanced by the high income household adjusting its savings rate. Thus the middle income household accepts the interest rate as given. However, their propensity to save (which is independent of the interest rate) has an influence on the amount the high income household saves. Thus the high income household determines the interest rate and with it the total capital stock, but the middle income households determine the capital share owned by the high income household.

Steady-state values of variables are denoted by a tilde. We first assume that $\widetilde{C^{c}}>0$ and then derive its validity range.

It follows from the high income household's Euler Equation (3) that

$$
\widetilde{r}=\frac{\rho_{c}}{(1-\tau)}
$$

and from its budget constraint (2) that

$$
\widetilde{C^{c}}=\rho_{c} \widetilde{K^{c}} .
$$

The steady-state level of public capital is given by:

$$
\widetilde{P}=\frac{1}{\delta_{P}} \tau \cdot \widetilde{r} \widetilde{K}
$$

From Equation (12) a steady-state relationship for the production factors $\widetilde{P}$ and $\widetilde{K}$ can be derived:

$$
\alpha \widetilde{P}^{\beta} \widetilde{K}^{\alpha-1} L^{1-\alpha}=\frac{\rho_{c}}{1-\tau}+\delta_{k} .
$$

Rearranging and inserting Equation (18) into Equation (19) gives an explicit expression for $K$ :

$$
\widetilde{K}^{\left(1-\left(\frac{\beta}{1-\alpha}\right)\right)}=L\left(\tau \frac{\rho_{c}}{\delta_{P}(1-\tau)}\right)^{\left(\frac{\beta}{1-\alpha}\right)}\left(\frac{\alpha}{\frac{\rho_{c}}{(1-\tau)}+\delta_{k}}\right)^{\left(\frac{1}{1-\alpha}\right)} .
$$

$\overline{K^{c}}=K$, then the model would be a neoclassical growth model with public capital in discrete time. The dynamics of public capital is such that the required stability properties carry over from the neoclassical growth model, where $C^{c}$ is a "jump variable". What does Equation (11) add to the dynamics of the case $K^{c}=K$ ? The only modification is that in Equations (2) and (3) the interest rate is lower than if $K^{c}$ was the only capital input (the revenue in Equation (8) stays a constant fraction of total output). This implies that there are no qualitative differences in the dynamics, only the steady-state value of $K^{c}$ is smaller than the Keynes-Ramsey level of capital $K$ by exactly $S$. This can be shown by transforming the original system by dividing all variables throuth $Y$, and noting that $\frac{K}{Y}=\frac{K^{c}}{Y}-\frac{1-\alpha}{1+\rho_{c}}$, which reduces the transformed system to three dimensions. 
Validity limit The above equations are only valid if both agents have positive capital and consumption (see the discussion at the beginning of this section). This is ensured as long as the middle income household's savings are smaller than the total capital, that is

$$
\frac{\widetilde{S}}{\widetilde{K}}=\frac{L \widetilde{w}}{\left(2+\rho_{w}\right) \widetilde{K}}=\frac{(1-\alpha)}{\alpha\left(2+\rho_{w}\right)}\left(\frac{\rho_{c}}{1-\tau}+\delta_{k}\right)<1,
$$

where Equations (8), (13) and (19) were used to obtain an expression in terms of parameters only. We use the ratio $\frac{\widetilde{S}}{\widetilde{K}}$ as an indicator for inequality below.

From Equation (21), one can derive that there exists a constant $\tau_{\text {lim }}<1$ for which the steady-state characterization of the agents' behavior is valid in exactly the interval $\left[0 ; \tau_{l i m}\right]$. The expression of $\tau_{l i m}$ is:

$$
\tau_{\text {lim }}=1-\rho_{c}\left(\frac{1-\alpha}{\alpha\left(2+\rho_{w}\right)-\delta_{k}(1-\alpha)}\right) .
$$

For the remainder of the analysis, we assume that all critical values of $\tau$ are within the interval on which the analysis is valid. We check numerically in Section 3.3 that this assumption holds for a wide range of parameters, including those that best represent developed economies in a stylized way.

We next describe the impact of the capital tax rate on the steady-state behavior.

\subsection{The effects of policy}

The three main results on the role of fiscal policy in our model are stated as three propositions below: a capital tax levied for public investment decreases inequality in wealth (Proposition 1), middle income households prefer a higher capital tax rate than high income households (Proposition 2) and there exists a Pareto-improving range of capital tax rates (Proposition 3).

Below, inequality and optimality for the two household types are exclusively discussed in terms of their wealth: This is sufficient as the consumption of the high income household and the old and young middle income household are linear functions of their wealth. For the case of the high income household this is due to Equation (17), for middle income household's consumption when young it is an immediate consequence of Equations (8-9) and for its consumption when old this follows from Equations (6) and (16).

The economic intuition behind the three propositions can be developed as follows: The first result is a consequence of the Pasinetti Paradox. The middle income household's savings are proportional to its wage income, which is proportional to total output. So the share of the middle income household's savings to total capital - the indicator for inequality - depends linearly on the ratio of total output to total capital. By the properties of the 
neoclassical production function, the output-capital ratio depends positively on the marginal productivity of capital. But the marginal productivity of capital increases for higher capital taxes, even independently of how the tax revenue is used. This follows from the Pasinetti behavior of the model - as the interest rate is fixed by the high income household's behavior to be an increasing function of the tax rate (see Equation (16)).

The second result is derived from the fact that total capital depends in a convex way on the capital tax. The relationship is determined by the counteracting effects of the distortion through the capital tax and the beneficial effect on spending it on public investment that also impacts the productivity of private capital positively. ${ }^{3}$ The maximal wealth of the middle income household then occurs for a higher capital tax value because his savings depend only on his labor income. His labor income depends monotonically on accumulated total private capital, but also on public capital, and the impact of the latter is always positive. The maximal wealth of the high income household occurs for lower capital values as a consequence of the first result. As the share of total capital belonging to the middle income household increases faster than total capital the higher the capital tax, the maximal wealth of the remainder, the share of the high income household, must be reached for lower values of the capital tax than the maximal total capital.

The third result is due to the fact that the economy has no productive public capital if the government does not finance it. Thus a small increase in public investment has a bigger positive effect for both household types than the distortionary effect of financing it. (See also Section 3.3. for a numerical analysis of this effect.)

Figures 1 and 2 summarize the analytic results.

Proposition 1. Capital taxation (used for public investment) decreases inequality in wealth: $\frac{\mathrm{d} \frac{K}{S}}{\mathrm{~d} \tau}>0$ for $0<\tau<1$.

Proof. By Equation (21),

$$
\frac{\widetilde{S}}{\widetilde{K}}=\frac{(1-\alpha)}{\alpha\left(2+\rho_{w}\right)}\left(\frac{\rho_{c}}{1-\tau}+\delta_{k}\right)
$$

which is increasing in $\tau$.

Proposition 2. Middle income households prefer a higher capital tax rate than high income households: for some threshold rate $\tau^{*}, \frac{\mathrm{d} \widetilde{S}(\tau)}{\mathrm{d} \tau}>0$ for $0<\tau<\tau^{*}+\epsilon$ and $\frac{\mathrm{d} \widetilde{K}^{C}(\tau)}{\mathrm{d} \tau}<0$ for $1>\tau>\tau^{*}-\epsilon$ for some $\epsilon>0$.

\footnotetext{
${ }^{3}$ This is the same trade-off between efficiency-enhancing public investment and the distortionary capital taxation study by Barro (1990) for a single infinitely-lived agent.
} 



Figure 1: The upper graph shows the size of the different private capital stocks for capital taxes between 0 and $80 \%$. Each capital stock has its maximum for a different value of the capital tax $\tau$. The high income household prefers a lower tax rate than the middle income household, with the capital tax rate that maximizes total capital in between (i.e. $\tau_{K_{c}}^{\max }<\tau_{K}^{\max }<\tau_{S}^{\max }$ ). The same happens for consumption as shown in the graph on the bottom.

Proof. Let $\tau^{*}$ be the value of $\tau$ that maximizes $K$ as a function of $\tau$ on $(0,1)$ : it can be calculated that for $\tau^{*}=\frac{\beta\left(\rho_{c}+\delta_{k}\right)}{\beta \delta_{k}+\rho_{c}}, K\left(\tau^{*}\right)=0$ and shown that $\frac{\mathrm{d} \widetilde{K}(\tau)}{\mathrm{d} \tau}>0$ for $\tau<\tau^{*}$ and $\frac{\mathrm{d} \widetilde{K}(\tau)}{\mathrm{d} \tau}<0$ for $\tau>\tau^{*}$ (see Appendix A).

By combining Equations (8), (13) and (18), we obtain:

$$
\widetilde{S}=\underbrace{\frac{1-\alpha}{2+\rho_{w}} L^{(1-\alpha)}\left(\frac{\rho_{c}}{\delta_{P}}\right)^{\beta}}_{=\vartheta}\left(\frac{\tau}{(1-\tau)}\right)^{\beta} \widetilde{K}^{\alpha+\beta} .
$$

Thus:

$$
\frac{\partial \widetilde{S}}{\partial \tau}=\vartheta\left(\frac{\tau}{1-\tau}\right)^{\beta}\left[\frac{\beta}{\tau(1-\tau)}+\frac{\alpha+\beta}{\widetilde{K}} \frac{\partial \widetilde{K}}{\partial \tau}\right] \widetilde{K}^{\alpha+\beta}
$$




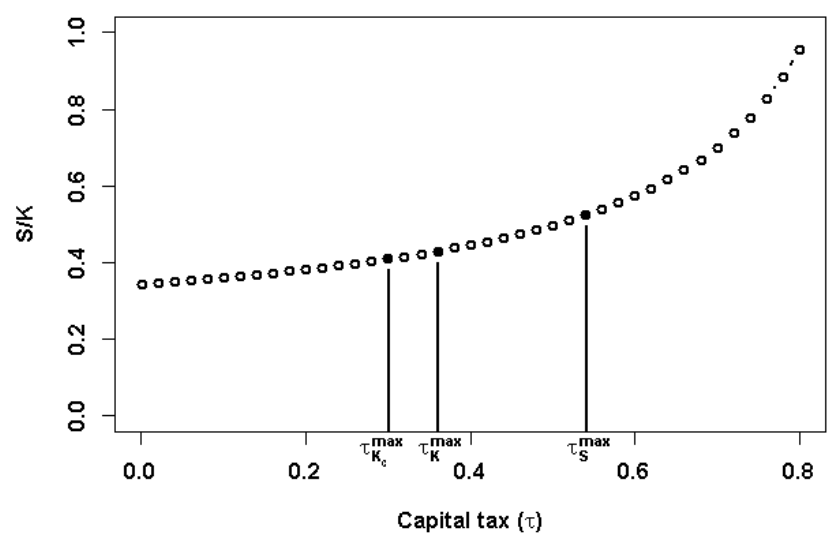

Figure 2: This graph illustrates Proposition 1: the middle income household's share of total capital increases within the validity range of capital taxes between 0 and $81 \%$.

Hence $\frac{\mathrm{d} S(\tau)}{\mathrm{d} \tau}>0$ for $0<\tau<\tau^{*}$. Also $\frac{\mathrm{d} S(\tau)}{\mathrm{d} \tau}$ is continuous and strictly positive at $\tau^{*}$, thus positive on $\left[\tau^{*}, \tau^{*}+\epsilon\right]$ for some $\epsilon$.

For a similar argument for $\widetilde{K}^{C}$, use that

$$
\widetilde{K}^{C}=\widetilde{K}\left(1-\frac{\widetilde{S}}{\widetilde{K}}\right) .
$$

For $1>\tau>\tau^{*}, \widetilde{K}^{C}$ is thus the product of two positive decreasing functions and hence $\frac{\mathrm{d} \widetilde{K}^{C}(\tau)}{\mathrm{d} \tau}<0$ there. At $\tau^{*}, \frac{\mathrm{d} \widetilde{K}^{C}(\tau)}{\mathrm{d} \tau}$ is strictly negative and continuous, hence it is also negative on $\left[\tau^{*}-\epsilon, \tau^{*}\right]$.

Proposition 3. There exists a Pareto-improving range of capital tax rates: $\frac{\mathrm{d} \widetilde{S}(\tau)}{\mathrm{d} \tau}>0, \frac{\mathrm{d} \widetilde{K}^{C}(\tau)}{\mathrm{d} \tau}>0$ for small $\tau>0$.

Proof. From Equation (24), $\frac{\mathrm{d} \widetilde{S}(\tau)}{\mathrm{d} \tau}>0$ is positive, if $\frac{\mathrm{d} \widetilde{K}(\tau)}{\mathrm{d} \tau}>0$ is, which is true for all $0<\tau<\tau^{*}$.

For $\widetilde{K}^{C}=\widetilde{K}\left(1-\frac{\widetilde{S}}{\widetilde{K}}\right)$, it is sufficient to prove that $\lim _{\tau \rightarrow 0} \frac{\mathrm{d} \widetilde{K}(\tau)}{\mathrm{d} \tau}>0$, because

$$
\frac{\mathrm{d} \widetilde{K}^{C}(\tau)}{\mathrm{d} \tau}=\frac{\mathrm{d} \widetilde{K}(\tau)}{\mathrm{d} \tau}\left(1-\frac{\widetilde{S}}{\widetilde{K}}\right)+\widetilde{K} \frac{\mathrm{d}}{\mathrm{d} \tau}\left(1-\frac{S}{K}\right)
$$

and the second summand goes to zero by Equation (23) as well as obtaining $\lim _{\tau \rightarrow 0} \widetilde{K}(\tau)$ from Equation (20). In fact, it can be shown that

$$
\lim _{\tau \rightarrow 0} \frac{\mathrm{d} \widetilde{K}(\tau)}{\mathrm{d} \tau}=\infty
$$


(See Appendix A).

\subsection{Simulation and calibration}

In the derivation of the three propositions above, we assumed that there is no public capital, when there are no taxes levied to finance it $\left(P_{0}=0\right)$. To relax this assumption, we present results from a numerical simulation. We also determine the tax values which cannot be calculated analytically, such as $\tau_{k_{c}}^{\max }$ and $\tau_{s}^{\max }$ and list the corresponding values for the distribution of capital between the agents $\frac{S}{K}$. We finally determine the range of each input parameter, within which the validity condition (22) from Section 3.1 holds.

The simulation yields that the results of Propositions 1-3 also hold for low to moderate base levels of the public capital stock and illustrates the dependency of optimal tax rates on different public capital productivities $\beta$. The results are summed up in Table 1 . The corresponding figures show the trajectories of capital $K, K^{C}$ and $S$ and consumption $C$ (Figure 1) and of capital ownership $\frac{S}{K}$ (Figure 2) for tax rates between 0 and $\tau_{\text {lim }}=0.81$.

\begin{tabular}{lcccccc}
\hline Parameter & $\tau_{k_{c}}^{\max }$ & $\tau_{k}^{\max }$ & $\tau_{s}^{\max }$ & $\frac{S}{K} \mid \tau_{k_{c}}^{\max }$ & $\frac{S}{K} \mid \tau_{k}^{\max }$ & $\frac{S}{K} \mid \tau_{S}^{\max }$ \\
\hline$\beta^{1}=0$ & 0 & 0 & 0 & 0.34 & 0.34 & 0.34 \\
$\beta^{2}=0.1$ & 0.16 & 0.2 & 0.37 & 0.37 & 0.38 & 0.43 \\
$\beta^{3}=0.2$ & 0.29 & 0.36 & 0.54 & 0.41 & 0.43 & 0.53 \\
$\beta^{4}=0.3$ & 0.41 & 0.49 & 0.64 & 0.45 & 0.49 & 0.62 \\
$\beta^{5}=0.4$ & 0.52 & 0.60 & 0.70 & 0.51 & 0.57 & 0.71 \\
$\beta^{6}=0.5$ & 0.63 & 0.69 & 0.75 & 0.60 & 0.68 & 0.80 \\
\hline \hline$P_{0}^{1}=0$ & 0.29 & 0.36 & 0.54 & 0.41 & 0.43 & 0.53 \\
$P_{0}^{2}=4$ & 0.14 & 0.24 & 0.48 & 0.37 & 0.39 & 0.48 \\
$P_{0}^{3}=8$ & 0 & 0.12 & 0.44 & 0.34 & 0.36 & 0.46 \\
$P_{0}^{4}=12$ & 0 & 0 & 0.40 & 0.34 & 0.34 & 0.45 \\
\hline
\end{tabular}

Table 1: Numerical results for varied public capital parameters $\beta$ and $P_{0}$. The table displays the capital tax values which maximize the different capital stocks and the ratio of middle income household's savings to total capital for these taxes. The highlighted rows correspond to the standard calibration, see Table (2) for the other parameter values.

The non-highlighted rows in Table (1) show the results for varied public capital productivity $(\beta)$, and varied initial public capital stock $\left(P_{0}\right)$, displaying the change in the numerical values for $\tau$ and $\frac{S}{K}$. The main results remain true up to a base level of public capital of $P_{0}<8$. For values $P_{0} \geq 8$, no Pareto-improvement through policy is possible anymore as further public investment is of no value to the high income household, who prefers a tax 
rate of 0 . For the case of totally unproductive public capital $(\beta=0)$ each agent prefers a tax rate of 0 .

A more extensive sensitivity analysis of all parameters of the model shows that for the ranges given in Table (2), the results obtained with the standard calibration are robust. In particular all capital stocks as functions of the capital tax rate reach their maximum within the model's validity limit for a large parameter range.

We calibrated the model so that for a capital tax of $21 \%$, which is the average capital tax rate in OECD countries between the years 1970 and 2000 (Carey and Rabesona, 2002), the distribution of wealth is as in Wolff (2010): in the U.S. in 2007, $62 \%$ of net worth are held by the top $5 \%$ of the population, almost $38 \%$ of net worth by the next $55 \%$, while the bottom 40 $\%$ hardly possess any net worth. The bottom cohort is left out of our analysis as it does not contribute to the aggregate capital stock. In accordance with findings on significant differences in intertemporal behavior of different income cohorts, the time preference rate of high income households is chosen lower than that of middle income households (Lawrance, 1991).

The capital's share of income $\alpha$ in the production function was chosen to be 0.38 . This is in accordance with observations by the OECD, that in 26 OECD countries with reliable data available, the labor share of income was dropping from $66.1 \%$ to $61.7 \%$ from 1990 to 2009 OECD (2012). Labor L, the total working hours, is a fixed factor in our model. Its value scales all variables: This can be seen from Equations (8), (9) and (10) for the overlapping generations household, from Equation (17) and (20) for the infinitely lived household and Equation (18) for the public good. We normalize labor $L=100$ and measure the other variables in this unit to obtain values in a convenient range. Time is measured in steps of 30 years, as middle income households are assumed to live for two periods.

\begin{tabular}{llcl}
\hline Parameter & Range & Standard value & Corresponding annual value \\
\hline$\rho_{c}$ & $0.2-1.6$ & 0.56 & $1.5 \%$ \\
$\rho_{w}$ & $3.0-8.0$ & 3.98 & $5.5 \%$ \\
$\delta_{k}$ & $0.3-1.7$ & 0.7 & $4 \%$ \\
$\delta_{P}$ & $0.3-3.1$ & 0.7 & $4 \%$ \\
$\beta$ & $0.0-0.5$ & 0.2 & $\mathrm{~N} / \mathrm{A}$ \\
$P_{0}$ & $0.0-5.0$ & 0.0 & $\mathrm{~N} / \mathrm{A}$ \\
\hline
\end{tabular}

Table 2: For values inside the range given in column two, the results of the model are economically meaningful: that is, the functions $K(\tau)$ and $S(\tau)$ reach their maximum within the validity range $\left(0<\tau<\tau^{\text {lim }}\right)$. In the third and fourth column the standard values used in the simulation and the corresponding yearly values are given. 


\section{Conclusion and outlook}

This paper shows that under stylized assumptions about heterogeneous saving behavior of households there is no simple efficiency-equity trade-off. We assume that the heterogeneity in saving behavior can be captured in three types of households: High income households save dynastically and their only source of income is capital interest. Middle income households save a portion of their wages for retirement. Low income households do not save and are irrelevant to the present analysis. Under this assumption we prove that public investment financed by capital taxation decreases inequality in wealth for any capital tax rate. Middle income households are in favor of a higher capital tax rate than high income households, but low capital tax rates constitute a Pareto-improvement over the unregulated outcome. We confirm numerically that these results still hold if there is positive aggregate production even without public investment. The results establish that under the heterogeneous saving behavior assumed in this article, balancing the goals of equity and efficiency is not a single trade-off, but is rather characterized by three stages. While the higher the tax, the more equal the wealth distribution, regarding the efficiency: (i) Low capital taxes (up to $29 \%$ in our model) increase consumption for both classes, there is no trade-off; (ii) higher capital taxes (up to $54 \%$ ) still increase aggregate output, but decrease consumption of high income households ${ }^{4}$; (iii) all even higher capital taxes decrease both household types' consumption.

There are two ways in which the analysis of this article could be extended: First, we only characterized potential policy interventions by their effect on inequality and consumption of the two types of households, eschewing the question which outcome is socially optimal. While the question of social optimality in overlapping generation models has been widely discussed (Calvo and Obstfeld, 1988; Heijdra, 2009), we do not know of any treatment of the role of a social planner in models with heterogeneous agents in which some households evolve as overlapping generations and some are infinitely-lived. Several reasonable normative viewpoints are conceivable in such a context. Defending one particular of them will need to answer the following question: With two household types having different time preference rates, does the time preference rate of the social planner only apply to the birth date of subsequent overlapping generations or should the utility of one or both household types also be discounted by this rate?

Second, the model employed in the present analysis relies on a set of very

\footnotetext{
${ }^{4}$ One might expect yet another stage: some range in which there is an increase in the income of the middle income households, but a decrease in aggregate output - which would represent the conventional view on equity and efficiency as conflicting goals. Such a stage does not exist in this model because there is no direct transfer to middle income households: When output decreases, both their capital and labor income also decrease.
} 
specific assumptions, introduced for isolating the effect of heterogeneous saving behavior and tractability. It seems desirable to enquire whether the results of this article also hold for more general production and utility functions (resulting in non-constant savings rate) and other forms of generating fiscal revenue, in particular labor taxation under non-fixed labor supply. Ongoing work suggests that the main results of this study hold under these more general assumptions (Klenert et al., 2014).

\section{Acknowledgments}

We thank Olga Heismann, Michael Jakob, Gregor Schwerhoff and Jan Siegmeier for useful comments. Financial support from the Michael-Otto-Stiftung for the Chair Economics of Climate Change at TU Berlin is gratefully acknowledged. Linus Mattauch thanks the German National Academic Foundation for financial support through a doctoral scholarship.

\section{A Derivations}

\section{A.1 Determining $\tau^{*}$}

Claim 1. At $\tau^{*}=\frac{\beta\left(\rho_{c}+\delta_{k}\right)}{\beta \delta_{k}+\rho_{c}}$ the function $\widetilde{K}(\tau)$ reaches its maximum on $(0,1)$. Proof. Let

$$
\gamma(\tau):=\left(\tau \frac{\rho_{c}}{\delta_{P}(1-\tau)}\right)^{\left(\frac{\beta}{1-\alpha}\right)}
$$

and

$$
\varphi(\tau):=\left(\frac{\alpha}{\frac{\rho_{c}}{(1-\tau)}+\delta_{k}}\right)^{\left(\frac{1}{1-\alpha}\right)} .
$$

It follows from Equation (20) that

$$
\frac{\partial \widetilde{K}}{\partial \tau}=\left(\frac{1-\alpha}{1-\alpha-\beta}\right)(L \cdot \gamma \cdot \varphi)^{\left(\frac{\beta}{1-\alpha-\beta}\right)} L \underbrace{\left(\frac{\partial \gamma}{\partial \tau} \varphi+\gamma \frac{\partial \varphi}{\partial \tau}\right)}_{=\Psi} .
$$

The derivatives of $\gamma$ and $\varphi$ are

$$
\frac{\mathrm{d} \gamma}{\mathrm{d} \tau}=\frac{\beta}{1-\alpha} \frac{1}{\tau(1-\tau)} \gamma
$$

and

$$
\frac{\mathrm{d} \varphi}{\mathrm{d} \tau}=-\frac{1}{\alpha(1-\alpha)} \frac{\rho_{c}}{(1-\tau)^{2}} \varphi^{(2-\alpha)}
$$

For $0<\tau<1$,

$$
\frac{\partial \widetilde{K}}{\partial \tau}=0 \Leftrightarrow \Psi=0
$$


since $\gamma \neq 0$ and $\varphi \neq 0$ for $\tau \in(0,1)$. From Equations (28) and (29) it follows that:

$$
\Psi=\frac{1}{1-\alpha} \cdot \gamma \cdot \varphi\left(\frac{\beta}{\tau(1-\tau)}-\frac{1}{\alpha} \frac{\rho_{c}}{(1-\tau)^{2}} \varphi^{(1-\alpha)}\right) .
$$

As

$$
\Psi=0 \Leftrightarrow \frac{\beta}{\tau(1-\tau)}=\frac{1}{\alpha} \frac{\rho_{c}}{(1-\tau)^{2}} \varphi^{(1-\alpha)},
$$

the tax value for the only critical point of $K$ on $(0,1)$ is

$$
\tau^{*}=\frac{\beta\left(\rho_{c}+\delta_{k}\right)}{\beta \delta_{k}+\rho_{c}} .
$$

To prove that $\widetilde{K}$ has a maximum at $\tau^{*}$, it can be verified that $\frac{\mathrm{d} \widetilde{K}}{\mathrm{~d} \tau}>0$ for $0<\tau<\tau^{*}$ and $\frac{\mathrm{d} \widetilde{K}}{\mathrm{~d} \tau}<0$ as follows: $\Psi$ is the factor which determines the sign of $\frac{\partial \widetilde{K}}{\partial \tau}$ on $(0,1)$. As $\gamma(\tau), \varphi(\tau)>0$ there,

$$
\Psi>0 \Leftrightarrow \frac{\beta}{\tau}>\frac{\rho_{c}}{\left(\rho_{c}+\delta_{k}(1-\tau)\right)} \Leftrightarrow 0<\tau<\tau^{*} .
$$

A.2 Determining $\lim _{\tau \rightarrow 0} \frac{\mathrm{d} \widetilde{K}(\tau)}{\mathrm{d} \tau}$

Claim 2. $\lim _{\tau \rightarrow 0} \frac{\mathrm{d} K(\tau)}{\mathrm{d} \tau}=\infty$.

Proof. In Equation (27) the second summand tends to zero. The first summand's behavior is determined by the product

$$
\frac{1}{\tau} \tau^{\frac{\beta}{(1-\alpha)}} .
$$

This product is multiplied by a factor $\tau^{\frac{\beta}{(1-\alpha-\beta)}}$, thus the overall relevant term for the behavior in the limit is

$$
\tau^{\frac{\beta}{(1-\alpha)}+\frac{\beta}{(1-\alpha-\beta)}-1}
$$

It can be calculated that the exponent of this factor has denominator $-1-2 \alpha+\alpha^{2}$. This shows the claim, as $\alpha<1$.

\section{References}

Alesina, A., Rodrik, D., 1994. Distributive politics and economic growth. The Quarterly Journal of Economics 109(2), 465-490.

Attanasio, O. P., 1994. Personal saving in the united states. In: Poterba, J. M. (Ed.), International Comparisons of Household Saving, pp. 57-124, The University of Chicago Press, Chicago. 
Barro, R. J., 1990. Government spending in a simple model of endogenous growth. Journal of Political Economy 98(5), 103-125.

Browning, M., Lusardi, A., 1996. Household saving: Micro theories and micro facts. Journal of Economic literature 34(4), 1797-1855.

Calvo, G. A., Obstfeld, M., 1988. Optimal time-consistent fiscal policy with finite lifetimes. Econometrica 56(2), 411-432.

Carey, D., Rabesona, J., 2002. Tax ratios on labour and capital income and on consumption. OECD Economic Studies 35(2), 129-174.

Chatterjee, S., Turnovsky, S. J., 2012. Infrastructure and inequality. European Economic Review 56(8), 1730-1745.

Dynan, K. E., Skinner, J., Zeldes, S. P., 2004. Do the rich save more? Journal of Political Economy 112(2), 397-444.

Heijdra, B. J., 2009. Foundations of Modern Macroeconomics. Oxford University Press, Oxford.

Klenert, D., Mattauch, L., Edenhofer, O., Lessmann, K., 2014. Why infrastructure investment reduces inequality, mimeo.

Lawrance, E. C., 1991. Poverty and the rate of time preference: evidence from panel data. Journal of Political Economy pp. 54-77.

Mankiw, N. G., 2000. The savers-spenders theory of fiscal policy. The American Economic Review 90(2), 120-125.

Michl, T. R., 2009. Capitalists, workers, and fiscal policy: a classical model of growth and distribution. Harvard University Press, Cambridge, MA.

Michl, T. R., Foley, D. K., 2004. Social security in a classical growth model. Cambridge Journal of Economics 28(1), 1-20.

OECD, 2012. Labour Losing to Capital: What Explains the Declining Labour Share?, chapter 3, pp. 109-161. OECD.

Pasinetti, L. L., 1962. Rate of profit and income distribution in relation to the rate of economic growth. The Review of Economic Studies 29(4), $267-279$.

Piketty, T., 2011. On the long-run evolution of inheritance: France 18202050. The Quarterly Journal of Economics 126(3), 1071-1131.

Piketty, T., 2014. Capital in the Twenty-First Century. Harvard University Press, Cambridge, MA. 
Piketty, T., Zucman, G., 2013. Capital is back: Wealth-income ratios in rich countries 1700-2010, available online at: http://piketty.pse.ens.fr/fr/ , Retrieved: 27/01/2014.

Romp, W., De Haan, J., 2007. Public capital and economic growth: A critical survey. Perspektiven der Wirtschaftspolitik 8(S1), 652.

Samuelson, P. A., Modigliani, F., 1966. The Pasinetti paradox in neoclassical and more general models. The Review of Economic Studies 33(4), 269301.

Wolff, E. N., 1998. Recent trends in the size distribution of household wealth. Journal of Economic Perspectives 12(3), 131-150.

Wolff, E. N., 2010. Recent trends in household wealth in the united states: Rising debt and the middle-class squeeze - an update to 2007. The Levy Economics Institute Working Paper Collection 589 . 